\title{
Work of breathing during arm bracing in normal male subjects
}

\author{
Tomoyuki Ogino, RPT, MSc, PhD¹, Kyoshi Mase, RPT, PhD², Shigefumi Murakami, RPT, MSc'1, Kazuhisa Domen, MD, PhD³
}

\begin{abstract}
T Ogino, K Mase, S Murakami, K Domen. Work of breathing during arm bracing in normal male subjects. Can J Respir Ther 2020;56:65-69. doi: $10.29390 /$ cjrt-2020-012.

Objective: Although chronic obstructive pulmonary disease patients get relief from their dyspnea by arm bracing, the mechanics of this effect are unknown. This study aimed to investigate the mechanisms by which arm bracing affects dyspnea by measuring the work of breathing (WOB) in the arm bracing posture.

Methods: Six normal male subjects were studied in two standing postures: erect and with their arms braced. For the arm bracing posture, the subjects leaned forward with their arms stretched and rested their hands on a platform. Respiratory frequency was set at 20 tidal breaths/min with the use of a metronome, and tidal volume was set at $1 \mathrm{~L}$ by observing the lung volume on a monitor. All the subjects randomly adopted the two postures, and a preset respiratory pattern was measured for $30 \mathrm{~s}$ in each posture. Lung volume and flow rate were measured using a hot-wire flowmeter. Esophageal pressure was measured using a $12-\mathrm{cm}$ balloon catheter. The WOB was estimated using modified Campbell diagrams.

Results: Lung volume increased and inspiratory resistive WOB decreased, while inspiratory elastic WOB increased significantly with arm bracing compared with that of the erect posture $(P<0.05)$.

Conclusion: Arm bracing posture increases the chest wall expansion thereby increasing the end-expiratory lung volume and decreasing the inspiratory resistive WOB among healthy individuals.
\end{abstract}

Key Words: arm bracing posture; work of breathing; Campbell diagram

\section{INTRODUCTION}

Chronic obstructive pulmonary disease (COPD) patients often use arm bracing as a postural method of gaining relief from dyspnea [1]. Adoption of the arm bracing and trunk-inclined posture reportedly relieves dyspnea through improvement of the function of the diaphragm $[1,2]$ and decreases the work of breathing (WOB) by changing the activity of accessory respiratory muscles by stabilizing the upper extremity $[3,4]$. The arm bracing posture also increases lung volume [5-7]. Furthermore, since airway resistance depends on lung volume $[7,8]$, decrease in airway resistance is also possible with arm bracing posture. However, no study has investigated WOB in the arm bracing posture.

This study aimed to investigate the mechanisms by which arm bracing affects dyspnea by measuring the WOB in the arm bracing posture.

\begin{abstract}
METHODS
Subjects

This study included six normal male subjects (age $34.5 \pm 6.7$ years, height $176.0 \pm 8.0 \mathrm{~cm}$, weight $67.0 \pm 4.6 \mathrm{~kg}$ ) with normal pulmonary function. A written informed consent was obtained in advance from all subjects for participating in this study. The study was approved by the Ethics Committee of Hyogo College of Medicine (approval number 1315). This study was also registered at the University Hospital Medical Information Network (No. UMIN000027965).
\end{abstract}

\section{Procedure and measurement}

Pre-intervention

Esophageal pressure $\left(\mathrm{P}_{\mathrm{es}}\right)$, as a pleural pressure indicator, was measured using a $12-\mathrm{cm}$ long balloon attached to one end of a polyethylene catheter (inner diameter, $1.5 \mathrm{~mm}$; length, $101 \mathrm{~cm}$ ); the other end of which was connected to a differential pressure transducer (Chest M. I., Inc., Osaka, Japan). The balloon was introduced transnasally into the stomach and then gradually withdrawn until a negative deflection was present during inspiration. The balloon was then withdrawn for another $10 \mathrm{~cm}$ and was secured at this level. Furthermore, the balloon position was adjusted to maintain $\mathrm{P}_{\mathrm{es}}$ at approximately $-5 \mathrm{~cm} \mathrm{H}_{2} \mathrm{O}$ at end-expiratory lung volume (EELV) in the sitting position. The balloon was inflated with $1 \mathrm{~mL}$ of air, and the occlusion test [9] was performed to ensure its correct placement.

Lung volume and flow rate were measured using a hot-wire flowmeter (AE300-s, Minato Medical Science Co., Ltd., Osaka, Japan). A nose clip was not used during the study, because a face mask was placed over the subject's nose and mouth and was tightly sealed with elastic straps around the head and neck (Figure 1).

Respiratory rate (RR) was set at 20 tidal breaths/min using a metronome, and tidal volume $\left(\mathrm{V}_{\mathrm{T}}\right)$ was set at $1 \mathrm{~L}[10,11]$. All subjects were directed to maintain this $\mathrm{V}_{\mathrm{T}}$ by observing a graphic display of their lung volume on a monitor. To obtain satisfactory technique and reproducibility of $R R$ and $V_{T}$, all subjects practiced before starting the measurements.

\section{During intervention}

For all subjects, their slow vital capacity (SVC) was first measured in the erect posture. Then, all the subjects adopted the two standing postures: erect and with arm bracing (Figure 1), and their respiratory parameters while breathing with the preset respiratory pattern mentioned below were measured for $30 \mathrm{~s}$ in each posture. The posture testing sequence was randomized according to a randomization schedule generated beforehand. For the arm bracing posture, the subjects leaned forward with their arms stretched and rested their hands on a platform whose height was set so that the subjects could assume the most comfortable

${ }^{1}$ Department of Rehabilitation, Hyogo College of Medicine Sasayama Medical Center, Sasayama, Hyogo, Japan;

${ }^{2}$ Department of Physical Therapy, Faculty of Nursing and Rehabilitation, Konan Women's University, Higashinada, Kobe, Hyogo, Japan;

${ }^{3}$ Department of Rehabilitation Medicine, Hyogo College of Medicine, Nishinomiya, Hyogo, Japan

Correspondence: Tomoyuki Ogino, RPT, MSc, PhD, Department of Rehabilitation, Hyogo College of Medicine Sasayama Medical Center, 5 Kurooka, Sasayama, Hyogo 669-2321, Japan. Tel.: +81 79 5527381, E-mail: ogino0327@gmail.com

Published online at https://www.cjrt.ca on 26 November 2020 


\section{FIGURE 1.}

The two postures evaluated in this study. A: erect. B: arm bracing.

(A)

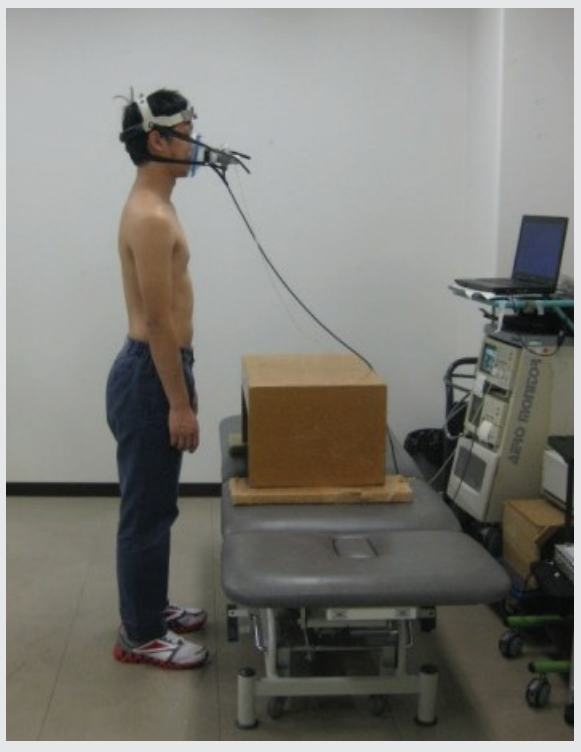

(B)

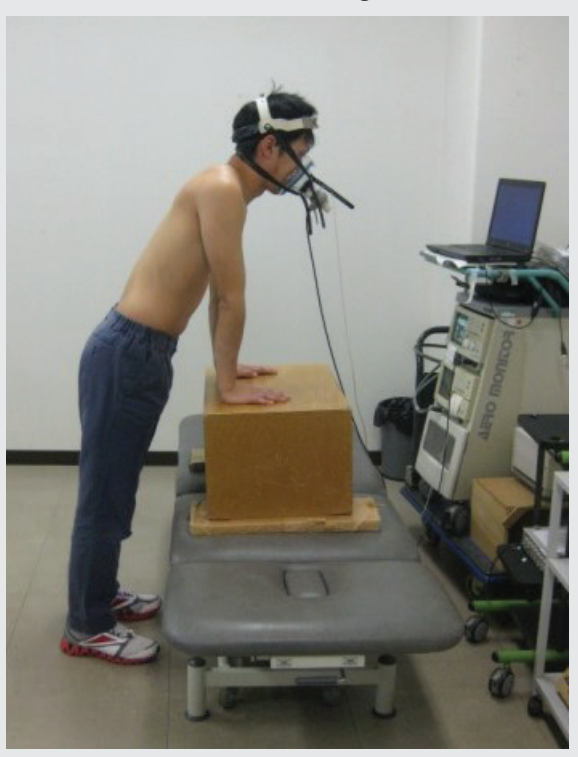

trunk inclination (average $33.3 \pm 6.1^{\circ}$ ). All subjects also performed the inspiratory capacity maneuver in the erect posture at the start and end of the measurements in the two postures, to correct possible "drift" caused by mechanical errors [12].

Lung volume, flow rate, and $\mathrm{P}_{\text {es }}$ were digitized at $100 \mathrm{~Hz}$ using an analyzing system (PowerLab; ADInstruments, Dunedin, New Zealand), and the data were stored on a computer.

\section{Post intervention}

In each posture, five stable breaths were analyzed breath-by-breath for each subject, and the mean $\Delta \mathrm{P}_{\mathrm{es}}$, WOB, dynamic lung compliance (Cdyn), end-inspiratory lung volume (EILV), and EELV were calculated. EILV and EELV were then normalized based on SVC being 100\%.

WOB was estimated using modified Campbell diagrams, which plots the relationship between $\mathrm{P}_{\mathrm{es}}$ and lung volume [13]. Figure 2 shows an example of the modified Campbell diagram. A line was drawn connecting the points of zero flow (EELV and EILV), representing the Cdyn. Cdyn was obtained from the following the equation:

$$
\text { Cdyn }=\mathrm{V}_{\mathrm{T}} / \Delta \mathrm{P}_{\mathrm{es}}
$$

The work done during a breathing cycle is represented as an area on the pressure-volume diagram. Therefore, WOB was obtained from the following the equation:

$$
\mathrm{WOB}=\int \mathrm{P}_{\mathrm{es}} \times \Delta \text { Volume }
$$

The work done by the inspiratory muscles to overcome flow resistance of the lung represents inspiratory resistive WOB, which is area ABCA (vertical hatching; Figure 2). The work needed to overcome lung elasticity represents inspiratory elastic WOB, which is area ACDEA (Figure 2). The sum of inspiratory resistive WOB and inspiratory elastic WOB represents the total inspiratory WOB (area ABCDEA, Figure 2; Supplementary appendix ${ }^{1}$ ). Additionally, in this study, EELV in each posture was assumed to be equal to functional residual capacity.

${ }^{1}$ The Supplementary Appendix is available on the journal website at https://www.cjrt.ca/wp-content/uploads/Appendix-2020-12.xlsx

\section{Statistical analysis}

Data are presented as medians (interquartile range). The reliability of the $\Delta \mathrm{P}_{\mathrm{es}}, \mathrm{WOB}$, and $\mathrm{Cdyn}$ in the erect and arm bracing postures was verified before starting the study. Reliability was analyzed using the intraclass correlation coefficient (ICC), classifying the values as low (ICC < 0.4), $\operatorname{good}(\mathrm{ICC}>0.4$ and < 0.75), and excellent (ICC > 0.75) [14].

Comparisons of breathing pattern, $\Delta \mathrm{P}_{\mathrm{es}}$, WOB, and Cdyn between the erect and arm bracing postures were performed using Wilcoxon signed-rank tests. Effect sizes were also calculated as $r[15,16]$. Cohen's guidelines for small $(r=0.10)$, medium $(r=0.30)$, and large $(r=0.50)$ effects were used to evaluate the magnitude of this effect size [17].

All tests were performed at a significance level of $P<0.05$. Analyses were performed with statistical software (SPSS 18; SPSS Inc., Chicago, IL, USA).

\section{RESULTS}

Table 1 shows the reliability of $\Delta \mathrm{P}$, WOB, and Cdyn in the erect and arm bracing postures. ICC values higher than 0.6 were found for $\Delta \mathrm{P}_{\mathrm{es}}$, WOB, and Cdyn in both postures $(P<0.05)$.

Table 2 shows the changes in breathing pattern, $\Delta \mathrm{P}_{\mathrm{es}}$, WOB, and Cdyn in both postures. Figure 3 shows the time traces of pressure, volume, and flow, and the modified Campbell diagram with each posture in a representative case. $R R, V_{T}$, minute ventilation $\left(V_{E}\right)$, and inspiratory and expiratory flows were not significantly different between the two postures. However, EILV and EELV increased significantly with arm bracing compared with that of the erect posture. Inspiratory resistive WOB decreased significantly with arm bracing compared with that of the erect posture. However, inspiratory elastic WOB increased significantly with arm bracing compared with that of the erect posture. Thus, total inspiratory WOB was significantly higher in the arm bracing posture than in the erect posture. $\Delta \mathrm{P}_{\text {es }}$ and Cdyn were not significantly different between the two postures.

\section{DISCUSSION}

The major findings of this study were that lung volume increased and inspiratory resistive WOB decreased with arm bracing compared with the erect posture. Lung volume has been seen to increase with arm bracing in previous studies [5, 6]. Craig [5] reported that arm bracing increased expiratory reserve volume by $3.1 \%$ and that inclining the trunk forward 


\section{FIGURE 2.}

Graphical analysis of work of breathing using the modified Campbell diagram. The vertical hatching area represents the inspiratory resistive work of breathing (area $A B C A$ ). The fine stippling area represents the inspiratory elastic work of breathing (area ACDEA). Cdyn, dynamic lung compliance; $\mathbf{P}_{\mathrm{es}}$, esophageal pressure; EILV, end-inspiratory lung volume; EELV, end-expiratory lung volume.

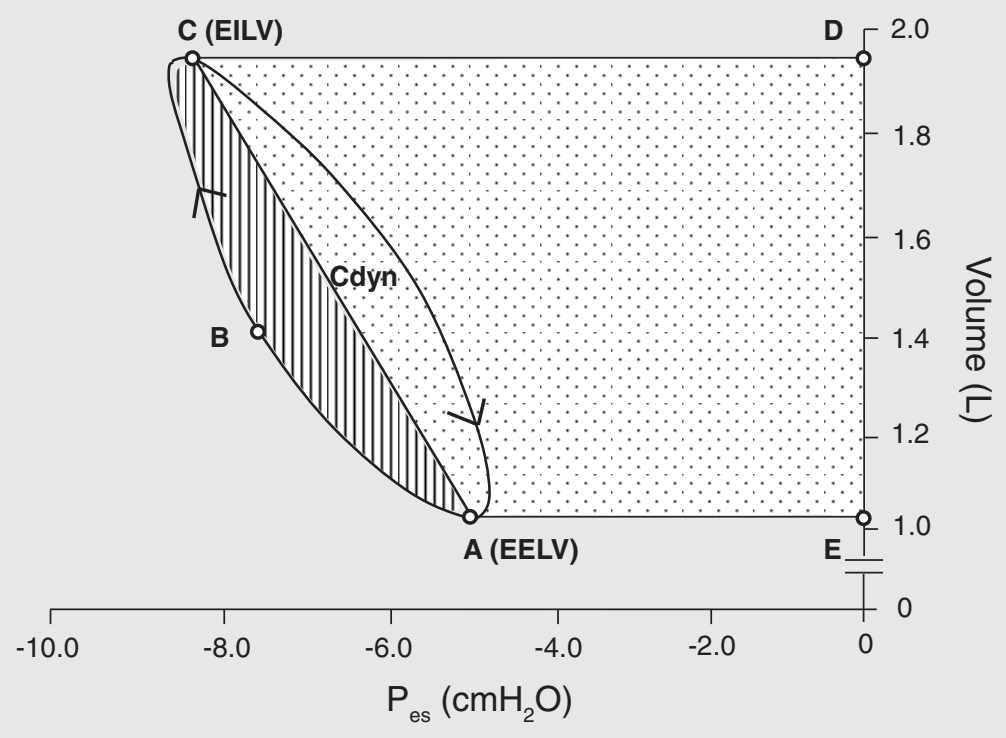

\section{TABLE 1}

Reliability of $\Delta \mathrm{P}_{\mathrm{es}}$, WOB, and Cdyn in the erect and arm bracing postures

\begin{tabular}{lccccc}
\hline & \multicolumn{2}{c}{ Erect } & & \multicolumn{2}{c}{ Arm bracing } \\
\cline { 2 - 3 } \cline { 6 - 7 } Variable & ICC (95\% Cl) & $\boldsymbol{P}$ & & ICC (95\% Cl) & $\boldsymbol{P}$ \\
\hline$\Delta \mathrm{P}_{\text {es }}$ & $0.66(-0.10-0.94)$ & 0.04 & & $0.67(-0.09-0.94)$ & 0.04 \\
Inspiratory elastic WOB & $0.82(0.26-0.97)$ & 0.01 & & $0.81(0.22-0.97)$ & 0.01 \\
Inspiratory resistive WOB & $0.82(0.24-0.97)$ & 0.01 & & $0.73(0.04-0.96)$ & 0.02 \\
Cdyn & $0.82(0.27-0.97)$ & 0.01 & & $0.75(0.07-0.96)$ & 0.02 \\
\hline
\end{tabular}

$\mathrm{P}_{\mathrm{es}}$,esophageal pressure; WOB, work of breathing; Cdyn, dynamic lung compliance; ICC, intraclass correlation coefficient; $\mathrm{Cl}$, confidence interval.

increased it further. Prandi et al. [6] found that arm bracing increased FRC by $300 \mathrm{~mL}$. From the relationship between the volume-pressure curves of the lung and chest wall, as the lung volume increases, the inward retractile force of the lung parenchyma increases, and the outward expansive force of the chest wall decreases. On the contrary, as the lung volume decreases, the inward retractile force of the lung parenchyma decreases, and the outward expansive force of the chest wall increases [18]. Therefore, at a lung volume that is equal to FRC, the outward expansive force of the chest wall balances the inward retractile force of the lung parenchyma. Also, a report showed that the FRC changes as posture changes [19]. In other words, the change in the relationship between the volume-pressure curves of the lung and chest wall is a factor. For example, when the posture changes from upright to supine position, the volume-pressure curve of the lung shifts to the left side and the volume-pressure curve of the chest wall shifts to the right side. Therefore, the inward retractile force of the lung parenchyma and the outward expansive force of the chest wall are reduced to maintain the balance; as a result, the FRC is reduced in supine position [18]. Also, in this study, the increased EELV in the arm bracing posture may have been caused by a change in the relationship between the volume-pressure curves of the lung and chest wall. Since no significant difference in Cdyn was found between erect and arm bracing postures in this study, the possibility that no difference in the volume-pressure curve of the lung between the erect and arm bracing postures was considered.
As a result, the change in EELV with arm bracing may be caused by greater chest wall expansion in the arm bracing posture as compared with that of the erect posture, which would likely result in an upward shift of the volume-pressure curve of the chest wall. Craig [5] estimated that by supporting the load of the arms and shoulder girdles, arm bracing reduces the load on the chest wall by $7-9 \mathrm{~kg}$. Thus, since the chest wall does not need to support the arms, it can expand to a greater degree so that lung volume can also increase [6]. Furthermore, the erect posture contracts the chest wall, changing the site of action of gravity on the chest wall to the pelvic direction. On the other hand, the action of gravity on the chest wall in the arm bracing posture changes to a forward position [20], which could also be a possible mechanism by which the arm bracing posture increases chest wall expansion.

In this study, the respiratory pattern was set based on previous studies $[10,11]$, because unifying the ventilation volumes was necessary to compare WOB in the erect posture with that of the arm bracing posture. On the other hand, higher RR and large $\mathrm{V}_{\mathrm{T}}$ have been reported to increase the expiratory resistive WOB and the expiratory elastic WOB [21]. Therefore, at the ventilation volume, measuring that the EELV did not decrease below FRC was necessary, because chest wall compliance could not be measured in this study and the expiratory resistive WOB and the expiratory elastic WOB could not be calculated. Additionally, a report showed that the inspiratory capacity did not change at twice the resting RR in normal subjects [11], and the protocol of this study was believed to be appropriate.

The observed decrease in inspiratory resistive WOB in the arm bracing posture may be secondary to the increase in lung volume. Airway resistance depends on lung volume: the higher the lung volume, the lower the airway resistance [7, 8]. Inspiratory resistive WOB is also related to forced vital capacity and peak expiratory flow [21]. Therefore, a possibility was considered that the increased lung volume with arm bracing decreases airway resistance, and consequently, decreases inspiratory resistive WOB. Moreover, the decreased inspiratory resistive WOB with arm bracing may be caused not by the change in breathing pattern but by the change in pulmonary resistance (due to dilation of airway diameter and decrease in tissue resistance), because no significant difference was found in $R R, V_{T}, V_{E}$, and flow between the two postures in this study. 
Ogino et al.

TABLE 2

Breathing pattern, $\Delta \mathrm{P}_{\mathrm{es}}$, WOB, and Cdyn in the erect and arm bracing postures

\begin{tabular}{|c|c|c|c|c|}
\hline & Erect & Arm bracing & $P$ & $r$ \\
\hline $\mathrm{RR}$, breaths/min & $20.0(19.8-20.0)$ & $19.9(19.9-20.1)$ & 0.79 & 0.11 \\
\hline$V_{T}, L$ & $1.0(1.0-1.0)$ & $1.0(1.0-1.0)$ & 1.00 & 0.00 \\
\hline $\mathrm{V}_{\mathrm{E}}, \mathrm{L} / \mathrm{min}$ & $19.5(19.2-19.7)$ & $19.5(19.0-19.9)$ & 0.60 & 0.22 \\
\hline Inspiratory flow, L/sec & $1.1(1.0-1.1)$ & $1.2(1.1-1.2)$ & 0.35 & 0.39 \\
\hline Expiratory flow, L/sec & $0.9(0.8-0.9)$ & $0.8(0.8-0.9)$ & 0.92 & 0.04 \\
\hline EILV, \% & $57.4(55.3-63.8)$ & $70.6(69.4-75.3)$ & 0.03 & 0.90 \\
\hline EELV, \% & $36.1(35.0-41.0)$ & $49.6(47.6-52.0)$ & 0.03 & 0.90 \\
\hline$\Delta \mathrm{P}_{\mathrm{es}}, \mathrm{cmH}_{2} \mathrm{O}$ & $3.4(2.8-3.6)$ & $3.7(3.1-4.6)$ & 0.17 & 0.56 \\
\hline Inspiratory elastic WOB, J/min & $142.9(126.9-158.5)$ & $212.4(201.5-232.7)$ & 0.03 & 0.90 \\
\hline Inspiratory resistive $\mathrm{WOB}, \mathrm{J} / \mathrm{min}$ & $30.2(29.4-31.6)$ & $24.3(21.8-25.3)$ & 0.03 & 0.90 \\
\hline Total inspiratory WOB, J/min & $173.3(159.6-183.9)$ & $237.5(222.0-259.6)$ & 0.03 & 0.90 \\
\hline Cdyn, $\mathrm{CmH}_{2} \mathrm{O}$ & $0.3(0.3-0.4)$ & $0.3(0.2-0.3)$ & 0.12 & 0.64 \\
\hline
\end{tabular}

Data are presented as median (interquartile range).

$\mathrm{RR}$, respiratory rate; $\mathrm{V}_{\mathrm{T}}$, tidal volume; $\mathrm{V}_{\mathrm{E}}$, minute ventilation; EILV, end inspiratory lung volume; EELV, end expiratory lung volume; $\mathrm{P}_{\text {es }}$, esophageal pressure; WOB, work of breathing; Cdyn, dynamic lung compliance.

\section{FIGURE 3.}

Representative time traces of pressure, volume, and flow and modified Campbell diagram obtained with the subject in the erect and arm bracing postures. The arm bracing posture results in a higher lung volume than in the erect posture. Inspiratory resistive work of breathing is lower in the arm bracing posture. However, inspiratory elastic work of breathing is higher in the arm bracing posture than in the erect posture. $P_{\mathrm{es}}$, esophageal pressure.

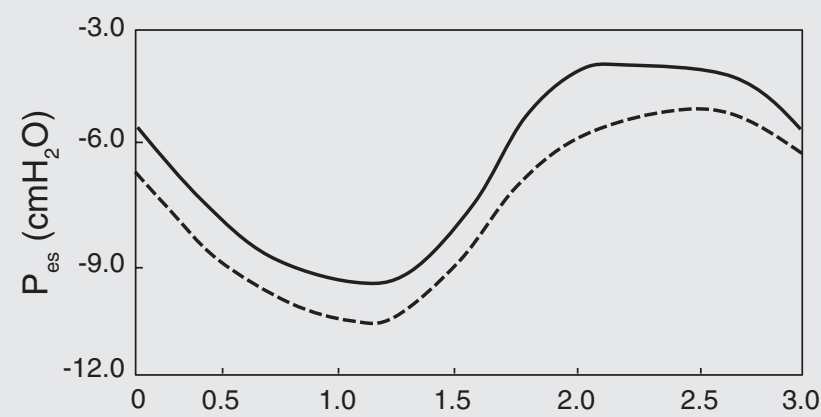

Erect
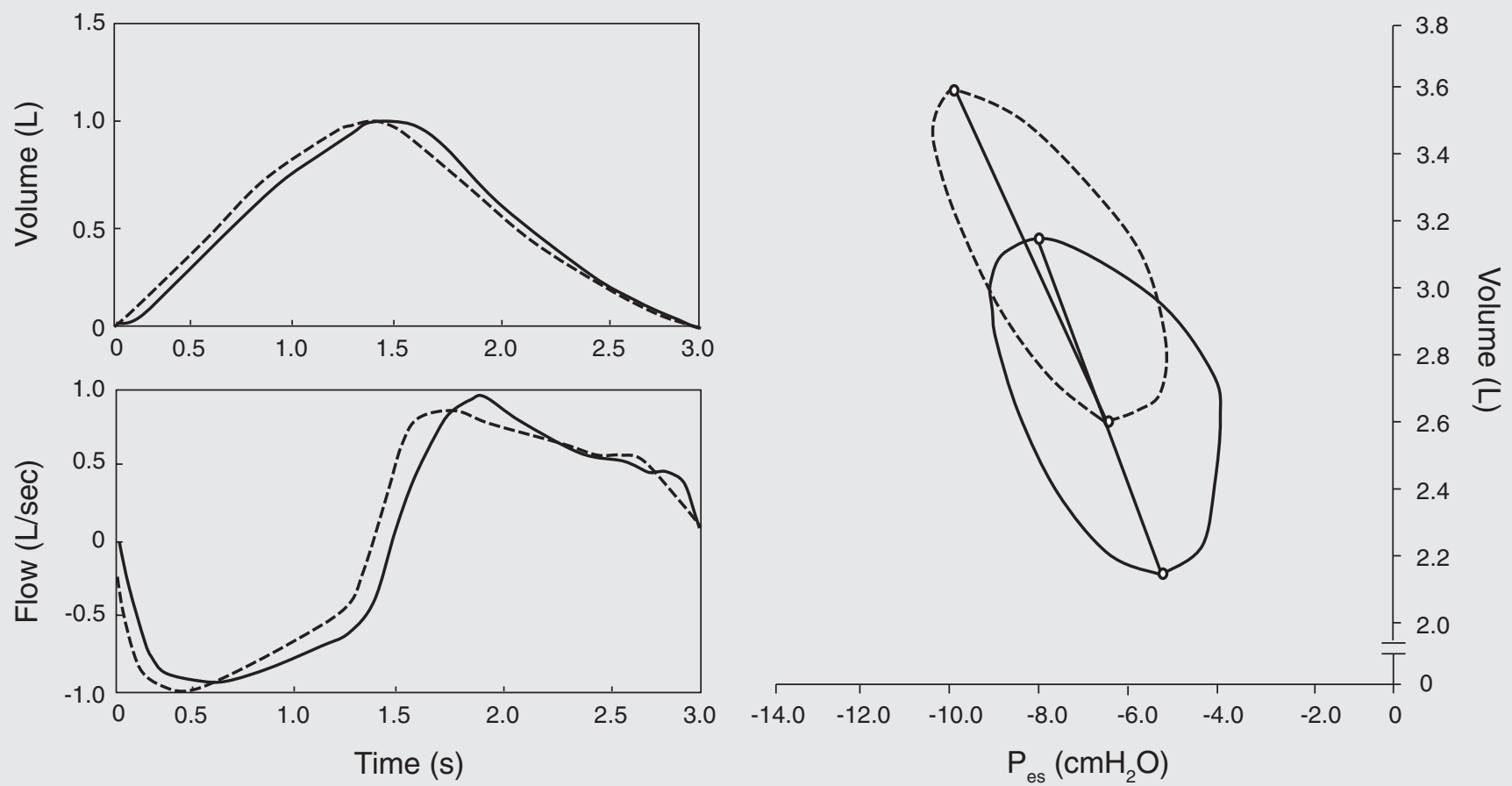
Furthermore, significant increase in inspiratory elastic WOB was observed in arm bracing posture compared with that of the erect posture, as also observed in total WOB. This may also have been caused by increased lung volume with arm bracing, because high-volume breathing increases the elastic recoil of the lungs [22]. However, the inspiratory elastic WOB was assumed to be the sum of the work done by the inspiratory muscles, and the elastic energy transferred from the chest wall to the lungs in this study, because chest wall compliance could not be measured. This was because reliably measuring chest wall compliance is very difficult because inexperienced subjects have a difficult time completely relaxing their respiratory muscles. Therefore, in their studies, Guenette et al. [21] and Sliwinski et al. [23] used measurements of chest wall compliance from previously published data. Guenette et al. [21] assumed that chest wall compliance is similar between trained and untrained subjects. They also counted on the fact that their subjects were similar in terms of relative fitness and respiratory function levels to those in the previous study. However, for us, using previously published data was difficult, because no study has investigated chest wall compliance in the arm bracing posture, and our subjects had different relative fitness and respiratory function levels compared with those of the previous study. Therefore, the effect of the arm bracing posture on inspiratory elastic WOB could not be determined accurately in this study.

On the other hand, COPD patients have a high WOB at rest, their resistive WOB being particularly high [24]. Therefore, the arm bracing posture may decrease WOB for disorders with increased airway resistance, such as COPD.

\section{Study limitations}

Although the WOB during arm bracing posture was estimated using the modified Campbell diagram [11], chest wall compliance could not be measured in this study. Furthermore, the estimated WOB in this study could also have been affected by the fact that EELV with both postures was assumed to be equal to the FRC. However, previous studies showed that the arm bracing posture increases lung volume [5, 6] and that airway resistance depends on lung volume [8]. Therefore, the results this study were believed to support the previously reported effects of the arm bracing posture. Moreover, the WOB may have been underestimated in this study, because the problem of gas compression and chest wall distortion was ignored. However, gas compression is typically negligible in normal subjects at rest and during exercise. Chest wall distortion also does not occur in normal subjects in the absence of added external respiratory loads, even at the values of ventilation achieved during heavy exercise [13]. Therefore, gas compression and chest wall distortion were believed to have had minimal effects in this study.

This study assessed the effect of the arm bracing posture in normal subjects and with a preset respiratory pattern. Additionally, this study was conducted with a small sample size and included only male subjects. Furthermore, dyspnea was not measured at this time because the subjects were healthy and did not feel any signs of dyspnea. Hence, the results cannot be directly extrapolated to patients with breathing difficulties, such as COPD. Further studies are required to address these issues.

\section{CONCLUSIONS}

This study investigated the mechanisms by which arm bracing affects dyspnea by measuring WOB in the arm bracing posture in normal male subjects. The EELV increased and inspiratory resistive WOB decreased in the arm bracing posture. Therefore, arm bracing posture increases the chest wall expansion thereby increasing the EELV and decreasing the inspiratory resistive WOB among healthy individuals.

\section{Author Contributions: \\ Conception and design: Ogino, Mase \\ Data acquisition: Ogino, Murakami, Mase \\ Data processing: Ogino, Mase \\ Data analysis: Ogino, Mase \\ Data interpretation: Ogino, Murakami, Mase \\ Drafting the article: Ogino, Mase, Domen}

\section{Conflict of interest statement}

The authors have no conflicts of interest to declare.

\section{Funding}

Funding support for this study was provided by the Grant-in-Aid for Graduate Students, Hyogo College of Medicine.

\section{REFERENCES}

1. Sharp JT, Drutz WS, Moisan T, Foster J, Machnach W. Postural relief of dyspnea in severe chronic obstructive pulmonary disease. Am Rev Respir Dis 1980;122(2):201-11.

2. O'Neill S, McCarthy DS. Postural relief of dyspnoea in severe chronic airflow limitation: relationship to respiratory muscle strength. Thorax 1983;38(8):595-600. doi: 10.1136/thx.38.8.595.

3. Kim KS, Byun MK, Lee WH, Cynn HS, Kwon OY, Yi CH. Effects of breathing maneuver and sitting posture on muscle activity in inspiratory accessory muscles in patients with chronic obstructive pulmonary disease. Multidiscip Respir Med 2012;7(1):9. doi: 10.1186/2049-6958-7-9.

4. Banzett RB, Topulos GP, Leith DE, Nations CS. Bracing arms increases the capacity for sustained hyperpnea. Am Rev Respir Dis 1988;138 (1):106-9. doi: 10.1164/ajrccm/138.1.106.

5. Craig $A B$ Jr. Effects of position on expiratory reserve volume of the lungs. J Appl Physiol 1960;15:59-61. doi: 10.1152/jappl.1960.15.1.59.

6. Prandi E, Couture J, Bellemare F. In normal subjects bracing impairs the function of the inspiratory muscles. Eur Respir J 1999;13(5):1078-85. doi: 10.1034/j.1399-3003.1999.13e23.x.

7. D’ Angelo E, Calderini E, Torri G, Robatto M, Bono D, Milic-Emili J. Respiratory mechanics in anesthetized paralyzed humans: effects of flow, volume, and time. J Appl Physiol 1989;67(6):2556-64. doi: 10.1152/ jappl.1989.67.6.2556.

8. Rubini A, Carniel EL, Parmagnani A, Natali AN. Flow and volume dependence of rat airway resistance during constant flow inflation and deflation. Lung 2011;189(6):511-8. doi: 10.1007/s00408-011-9318-z.

9. Baydur A, Behrakis PK, Zin WA, Jaeger M, Milic-Emili J. A simple method for assessing the validity of the esophageal balloon technique. Am Rev Respir Dis 1982;126(5):788-91.

10. Fujimoto K, Yoshiike F, Yasuo M, et al. Effects of bronchodilators on dynamic hyperinflation following hyperventilation in patients with COPD. Respirology 2007;12(1):93-9. doi: 10.1111/j.1440-1843.2006.00936.x.

11. Gelb AF, Gutierrez CA, Weisman IM, Newsom R, Taylor CF, Zamel N. Simplified detection of dynamic hyperinflation. Chest 2004;126(6):185560. doi: 10.1378/chest.126.6.1855.

12. Johnson BD, Weisman IM, Zeballos RJ, Beck KC. Emerging concepts in the evaluation of ventilatory limitation during exercise: the exercise tidal flow-volume loop. Chest 1999;116(2):488-503. doi: 10.1378/chest.116.2.488.

13. Roussos C, Campbell EJM. Respiratory muscle energetics. In Macklem PT, Mead J, eds. Handbook of physiology. Bethesda: American Physiological Society; 1986. p. 481-509.

14. Flesis JL. The design and analysis of clinical experiments. New York, NY: John Wiley; 1986.

15. Portney LG, Watkins MP, Appendix C. Power and sample size. In Mehalik C, Cohen M, eds. Foundations of clinical research: applications to practice. 2nd ed. Upper Saddle River, NJ: Prentice Hall; 2000. p. 705-29.

16. Field A. Discovering statistics using SPSS. 2nd ed. London: Sage Publications; 2005.

17. Cohen J. Statistical power analysis for the behavior sciences. 2nd ed. Hillsdale: Lawrence Erlbaum; 1988.

18. Harris RS. Pressure-volume curves of the respiratory system. Respir Care 2005;50(1):78-98; discussion 98-9.

19. Agostoni E, Hyatt RE. Static behavior of the respiratory system. In: Geiger SR, ed. Handbook of physiology, 2nd ed. Bethesda: American Physiological Society; 1986. p. 113-30.

20. Vellody VP, Nassery M, Druz WS, Sharp JT. Effect of body position change on thoracoabdominal motion. J Appl Physiol Respir Environ Exerc Physiol 1978;45(4):581-9. doi: 10.1152/jappl.1978.45.4.581.

21. Guenette JA, Querido JS, Eves ND, Chua R, Sheel AW. Sex differences in the resistive and elastic work of breathing during exercise in endurance-trained athletes. Am J Physiol Regul Integr Comp Physiol 2009;297(1):R166-75. doi: 10.1152/ajpregu.00078.

22. O'Donnell DE, Webb KA. Exertional breathlessness in patients with chronic airflow Limitation: the role of lung hyperinflation. Am Rev Respir Dis 1993;148(5):1351-7. doi: 10.1164/ajrccm/148.5.1351.

23. Sliwinski P, Kaminski D, Zielinski J, Yan S. Partitioning of the elastic work of inspiration in patients with COPD during exercise. Eur Respir J 1998;11(2):416-21. doi: 10.1183/09031936.98.11020416.

24. Loring SH, Garcia-Jacques M, Malhotra A. Pulmonary characteristics in COPD and mechanisms of increased work of breathing. J Appl Physiol 2009;107(1):309-14. doi: 10.1152/japplphysiol.00008. 